\title{
Helping youth prevent HIV: An evaluation of the Straight Talk program in Uganda
}

Susan E. Adamchak

Karusa Kiragu

Cathy Watson

Medard Muhwezi

Tobey Nelson Sapiano

See next page for additional authors

Follow this and additional works at: https://knowledgecommons.popcouncil.org/departments_sbsr-hiv

Part of the Demography, Population, and Ecology Commons, Family, Life Course, and Society Commons, Gender and Sexuality Commons, International Public Health Commons, and the Medicine and Health Commons How does access to this work benefit you? Let us know!

\section{Recommended Citation}

Adamchak, Susan E., Karusa Kiragu, Cathy Watson, Medard Muhwezi, Tobey Nelson Sapiano, Ann AkiaFiedler, Richard Kibombo, and Milka Juma. 2008. "Helping youth prevent HIV: An evaluation of the Straight Talk program in Uganda," Horizons Research Summary. Washington, DC: Population Council. 


\section{Authors}

Susan E. Adamchak, Karusa Kiragu, Cathy Watson, Medard Muhwezi, Tobey Nelson Sapiano, Ann AkiaFiedler, Richard Kibombo, and Milka Juma 


\section{Helping Youth Prevent HIV: An Evaluation of the Straight TALK Program IN Uganda}

Mass media initiatives are being implemented globally to provide information and foster HIV preventive behavior. However, there has been limited evaluation of these efforts in sub-Saharan Africa. The Straight Talk program in Uganda has targeted youth with HIV and reproductive health information for over a decade. Evaluation results show positive associations between exposure to Straight Talk media and a number of key outcomes among youth, including sexual behavior, knowledge, and attitudes.<smiles>[Tl]</smiles>
he Straight Talk (ST) program is considered one of the most successful ongoing media

1 efforts to bring information about HIV and reproductive health to youth. But are its messages reaching youth, and is exposure to them having a positive impact on young people's attitudes and practice of safe behaviors?

In 2005-2006, the Horizons Program conducted the first impact evaluation of the ST program in Uganda

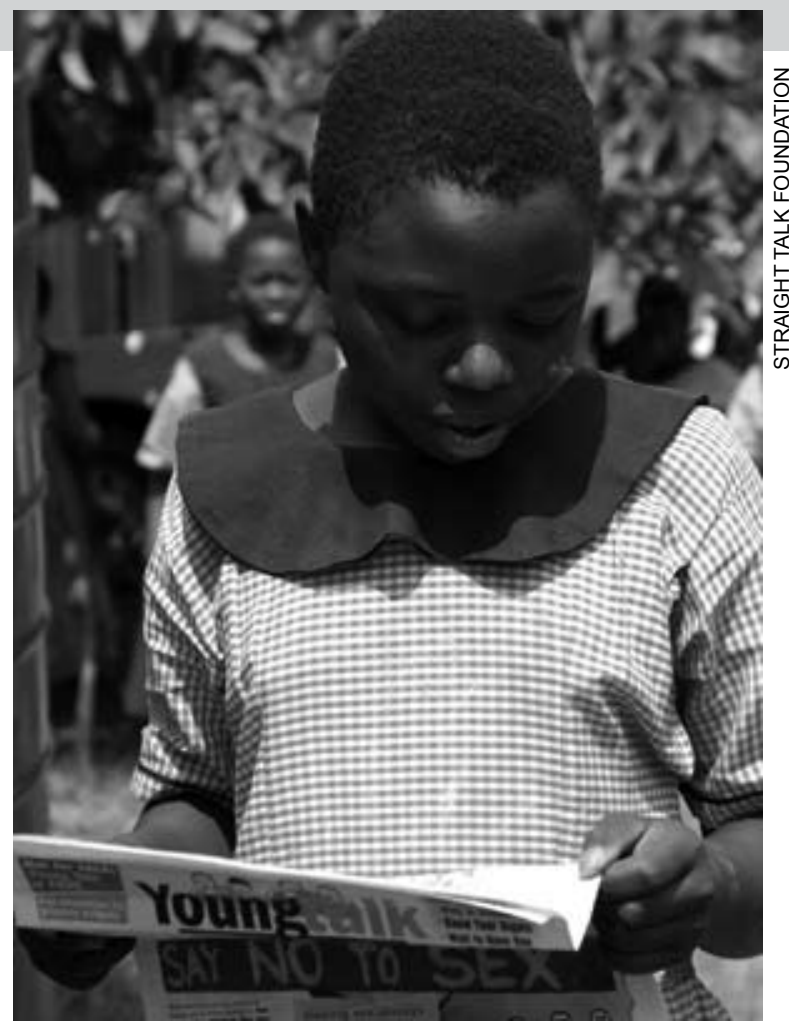

An adolescent girl reads Young Talk, an English language newspaper produced by Straight Talk.

to document its effects on young people, with a particular focus on the relationships between exposure to Straight Talk media and positive behaviors. The evaluation had several components: a household survey of adolescents, a household survey of parents, an assessment of the school environment, and a cost study ${ }^{1}$. This summary focuses on the findings of the adolescent survey.

To read more about this study, go to www.popcouncil.org/horizons/projects/Uganda_StraightTalk.htm 


\section{The Straight Talk Program}

The ST program uses three media products to reach youth: a multilingual Straight Talk Radio Show, a multilingual Straight Talk newspaper, and an English language Young Talk newspaper. ST media are designed to be audience-specific, with Young Talk newspaper aimed at primary school students, Straight Talk newspaper aimed at secondary school students, and Straight Talk Radio Shows aimed at older adolescents including those who are out of school and those who cannot read. Straight Talk also implements a wide array of schoolbased and community activities.

\section{Study Methods}

To evaluate the program, Horizons conducted an adolescent household survey in six districts in Uganda (Apac, Arua, Ntungamo, Soroti, Kisoro, and Kamuli) with 2,040 males and females between the ages of 10 and 19 years. While ST has been active in all six districts, it has been particularly active in the first four ${ }^{2}$. The study therefore allowed an assessment of the impact of ST in four high intensity and two low intensity districts. It also allowed for an assessment of the impact of incremental exposure to ST products on specific outcomes (i.e., dose response).

After obtaining informed consent from the adolescents and their parents/guardians, the researchers conducted face-to-face interviews with youth. Data analysis employed bivariate and multivariate methods and was conducted separately for males and females. Multivariate logistic regression controlled for age, access to radio, urban-rural residence, living arrangements, and schooling status (in school versus out of school).

\section{Respondent Profile}

Of the 2,040 adolescents in the survey, half were male, and the mean age was 14.5 years. About a quarter of the sample resided in urban areas, which is higher than the average of 15 percent for the whole population of Uganda. About 80 percent of respondents were either Catholic or Protestant. Slightly less than two-thirds of the youth lived with both parents, and those that lived

\section{Key Findings}

\section{$S T$ products and messages are reaching youth.}

Seven out of ten young people surveyed reported having seen or heard at least one ST product. Virtually all secondary and two-thirds of primary school respondents as well as 56 percent of out-of-school youth had been exposed to ST media. The Straight Talk Radio Show was the most popular product, followed by Young Talk newspaper and Straight Talk newspaper. The availability of ST products in a local language doubled exposure, from 42 percent among adolescents residing in districts where ST produced English-language-only media, to 84 percent where ST also offered products in a local language.

Nearly 60 percent of exposed adolescents reported that the main message they had obtained from ST products was abstinence, indicating that ST programming encouraged young people not to rush into sex. When asked what they were doing as a result of exposure to ST products, the most common response was "continuing to abstain," with nearly 70 percent of both males and females offering this reply. Fifteen percent of males and 12 percent of females said they stopped having premarital sex.

\section{Exposure to $S T$ products is linked to less sexual activity, particularly among males.}

About a quarter of the youth surveyed reported that they had a boyfriend or girlfriend, and 12 percent of the study sample reported ever having had sex (15 percent of males and 9 percent of females). Based on multivariate analysis, the study found that males exposed to all three ST products were only 39 percent as likely to be sexually experienced as their unexposed counterparts. 
More than half (56 percent) of sexually experienced males and 70 percent of sexually experienced females had only had one sexual partner in their lives. Many sexually experienced youth were practicing secondary virginity and had not had sex in the 12 months preceding the survey (38 percent of males and 41 percent of females). Multivariate analysis showed that males at the highest level of exposure to ST products were three times as likely to report not having sex in the past year compared to unexposed males. The pattern among females was not clear, in part due to the small number of sexually experienced females.

\section{Males exposed to ST media are more likely to take their relationships seriously.}

When asked about their intentions with their current sexual partner, just over a quarter of sexually experienced respondents said that they planned to marry him/her, including 29 percent of males and 28 percent of females. Older youth, those in secondary school, and those out of school were more likely to report marital plans. A further 7 percent said they were only dating their partners, while the rest said they had "no plans," were "just friends," or didn't know about their plans. For multivariate analysis, those who were planning to marry or said they were dating were considered as having a serious relationship. Logistic regression results showed that ST exposure was associated with a greater likelihood of respondents considering their current relationship "serious" among males (OR 20.2) but not among females, who may be more likely to consider their relationships serious regardless of their exposure to ST. Thus exposure to ST was associated with a greater likelihood of commitment among males.

\section{Exposure to $S T$ products is associated with con- dom use and positive attitudes toward condoms.}

Exposure to ST products was associated with greater condom use; 56 percent of those exposed to three ST products said they used condoms at last sex, compared to 24 percent of those with no exposure. However, the relationship was not statistically significant, largely due to the small sample size of condom users which limited regression analysis. Half of the sexually experienced females and 41 percent of sexually experienced males reported using condoms at last intercourse. While twothirds of the sexually experienced males reported being responsible for using condoms, more than half of their female peers also reported taking the initiative to use them.

In addition to condom use, respondents were asked about their attitudes toward condoms, such as whether females who carried them were "loose" and whether using them was a sign of mistrust. Multivariate analysis showed exposure to ST was associated with youth holding favorable attitudes toward condoms. Adolescents who were exposed to all three products were the most likely to hold positive views, while those exposed to only two items were around two times as likely. This pattern was found among both males and females.

\section{Youth exposed to $S T$ products are more likely to be tested for HIV.}

Seven percent of the adolescents surveyed, including 17 percent of sexually experienced respondents, had been tested for HIV. Urban and older youth were more likely to have been tested (and most likely to be sexually experienced). Exposure to ST was associated with having been tested, especially among those exposed to all three ST products, and with knowing whether a partner had been tested. Multivariate analysis shows that respondents exposed to all three ST products were more than three times as likely to have been tested for HIV.

\section{Exposure to $S T$ products is associated with being more knowledgeable about reproductive health.}

Multivariate analysis showed that greater exposure to ST products was significantly associated with reproductive health knowledge, and that each incremental exposure was associated with increased knowledge. Adolescents who were exposed to two items were 2.15 times more likely to score higher on a knowledge index than those who were not exposed, and those exposed to all three items examined were 2.72 times more likely to be better informed than their unexposed counterparts. The same pattern was observed for males and females. However, the survey results also show that there still remains considerable room for improvement in the level of adolescent HIV and reproductive health knowledge. One out of five adolescents wrongly believed that AIDS can be cured, only 46 percent of adolescents believed that females can get pregnant at first sex, and only 61 percent believed that condoms are effective against STIs if used correctly. 


\section{Exposure to $S T$ products is associated with greater communication with parents.}

Youth were asked whether their parents/guardians had ever talked with them about "sexuality, growing up, relationships between boys and girls, etc." Nearly half of the respondents reported having had conversed with a parent or guardian on these topics, with females (54 percent) more likely to report this than males ( 42 percent).

ST exposure was significantly associated with ever having talked with parents about reproductive health matters. Compared to those not exposed, females exposed to one product were 2.32 times more likely to have ever talked with a parent or guardian, those exposed to two products were slightly more likely (2.67 times) to have done so, and those exposed to three products were most likely (4.03 times). For males, the pattern was in the desired direction, but statistical significance was not achieved until they had been exposed to two or more products.

\section{Exposure to $S T$ products is associated with greater self-confidence and gender equitable at- titudes among females.}

Females exposed to two or three ST products were about one-and-a-half times more likely to report greater self-confidence than those who were not exposed to any product. This included feeling as important in their family network as other members and feeling less likely to doubt they had a bright future. Similarly, females were significantly more likely $(\mathrm{p} \leq 0.05)$ to have more gender equitable attitudes as their exposure to ST media increased. These patterns were not significant for males.

\section{Conclusion}

This study demonstrates that ST has become an important influence on the HIV and reproductive knowledge, attitudes, and behaviors of Ugandan adolescents. The program has good reach, with 70 percent of the young people surveyed exposed to at least one ST product.
Overall, the study indicates that many Ugandan adolescents have benefited from ST products, and that greater exposure was associated with greater benefits. This includes less sexual activity among exposed males, and higher levels of HIV testing and reproductive health knowledge among exposed youth.

The study found a number of gender differences: ST products were associated with certain positive outcomes among males alone, and others among females alone.

The ST program is using these and other results of the Horizons' evaluation to strengthen the successful elements of its activities and to address gaps. In particular, ST is strengthening its local language coverage, based on the finding that adding this component doubled the level of exposure to the program. $\mathcal{X}$

February 2008

${ }^{1}$ These reports are available from http://www.straight-talk.or.ug/downloads/ downloads.html

${ }^{2}$ In Apac, Arua, Ntungamo, and Soroti, STF has both English language as well as vernacular radio and print media activities. In Kisoro and Kamuli, ST media are only available in English.

The research team would like to thank Straight Talk Foundation (STF) for their exceptional support including Cathy Watson, Anne Akia Fiedler, Medard Muhwezi, and the entire Monitoring and Evaluation Section. The team would also like to thank the entire School Environment Program department at STF especially Beatrice Bainomugisha and Peter Mubala. Special appreciation is extended to the teachers and learners who answered the questions in the survey. The authors are grateful to the United States Agency for International Development and the Department for International Development for funding this evaluation.

The study team inluded: Karusa Kiragu, Horizons/PATH and Tobey Nelson Sapiano, Horizons/ICRW (principal study investigators); Richard Kibombo, independent consultant at Makerere University (data collection supervisor); and Scott Geibel, Horizons/Population Council (data analyst).

Suggested citation: Adamchak, Susan E., Karusa Kiragu, Cathy Watson, Medard Muhwezi, Tobey Nelson Sapiano, Ann Akia-Fiedler, Richard Kibombo, and Milka Juma. 2008. "Helping youth prevent HIV: An evaluation of the Straight Talk program in Uganda," Horizons Research Summary. Washington, DC: Population Council.

\section{Hprizons N}

Population Council/Horizons

Communications Unit

4301 Connecticut Avenue, NW

Suite 280

Washington, DC 20008

\section{Population Council}

Tel: $202-237-9400$

Fax: 202-237-8410

horizons@popcouncil.org

www.popcouncil.org/horizons
This research summary is made possible by the generous support of the American people through the United States Agency for International Development (USAID) and the President's Emergency Plan for AIDS Relief under the terms of HRN-A-00-97-00012-00. The contents are the responsibility of the Horizons Program and do not necessarily reflect the views of USAID or the United States Government. 